\title{
Evaluation of the Diameter Influence on the Tensile Strength of Pineapple Leaf Fibers (PALF) by Weibull Method
}

\author{
Maria Carolina Andrade Teles ${ }^{a}$, Gabriel Oliveira Glória ${ }^{a}$, Giulio Rodrigues Altoé \\ Pedro Amoy Netto ${ }^{a}$, Frederico Muylaert Margem ${ }^{a}$, Fabio Oliveira Braga ${ }^{b}$, Sergio Neves Monteiro ${ }^{b *}$ \\ ${ }^{a}$ Laboratório de Materiais Avançados - LAMAV, Universidade Estadual do Norte Fluminense \\ Darcy Ribeiro - UENF, Av. Alberto Lamego, 2000, CEP 28013-602, Campos dos Goytacazes, RJ, Brazil \\ ${ }^{b}$ Departamento de Ciência dos Materiais, Instituto Militar de Engenharia - IME, \\ Praça General Tibúrcio, 80, Praia Vermelha, Urca, CEP 22290-270, Rio de Janeiro, RJ, Brazil
}

Received: December 5, 2014; Accepted: November 11, 2015

\begin{abstract}
The fiber extracted from pineapple leaf (PALF) displays relevant mechanical properties that are motivating investigations for possible engineering application as polymer composite reinforcement. As any natural lignocellulosic fiber, the PALF presents non-uniform dimensions and heterogeneous properties with a significant dispersion of values. In fact, a marked variation in the tensile strength has been reported, which represents a problem for the design of a PALF reinforced composite. In several other lignocellulosic fibers, the diameter dimension was found to affect the value of the tensile strength. This work investigated the precise diameter dependence of the PALF tensile strength using the Weibull statistic method. The results showed a mathematical hyperbolic type of inverse correlation between the PALF strength and its diameter, which was found to be similar to that commonly obtained in other lignocellulosic fibers.
\end{abstract}

Keywords: pineapple leaf fiber, PALF, tensile strength, Weibull analysis

\section{Introduction}

Since the past century, composites became the fast growing class of materials for engineering applications. They can be projected through the combination of distinct phases, to attend specific requirements not possible to be achieved by a single conventional ceramic, polymer or metallic alloy ${ }^{1}$. In particular, polymer composites reinforced with strong synthetic fibers such as glass, carbon and aramid are nowadays extensively used in practically all engineering sectors, from simple surfboards and house appliances to high-tech medical prosthesis and aerospace components ${ }^{2-4}$. Synthetic fibers, however, are associated with some environmental and economical disadvantages. For instance, their production is costly and energy-intensive, which might be related to $\mathrm{CO}_{2}$ emission in the case of consuming electricity from thermoelectric power. Moreover, synthetic fiber-based products cannot be easily recycled and, thus, may be responsible for long-term pollution after their discard at the end of operational life. Both $\mathrm{CO}_{2}$ emission and worldwide pollution are becoming serious environmental problems affecting global warming and climate changes ${ }^{5}$. In addition, glass fiber processing and handling, as leftover, are hazardous procedures that may cause lung diseases.

In this decade, investigations and engineering application on natural lignocellulosic fibers extracted from cultivated plants have challenged the predominant use of synthetic fibers $^{6-17}$. While still today carbon fibers in high-tech composite

*e-mail: snevesmonteiro@gmail.com applications such as aircrafts cannot yet be substituted, glass fiber in common polymer composites are being successfully replaced by lignocellulosic fibers ${ }^{18-20}$. Indeed, automobiles are increasingly using lignocellulosic fiber composites not just as an environmentally friendly advertising but mainly because of technical advantages ${ }^{21-23}$ and restricted legislation ${ }^{24}$. Figure 1 illustrates a modern automobile together with several of its components made of polymer matrix composites reinforced with lignocellulosic fibers.

The current preference for lignocellulosic fiber composites is justified by their comparatively lower cost and density. Moreover, technical reasons such as less damage to processing tools and molding equipments as well as better finishing of automobile parts, Figure 1, favor the engineering application of these composites. In addition, relatively higher toughness and superior strength in comparison with the polymer matrix motivate their use as structural parts ${ }^{12}$.

Many well known lignocellulosic fibers have, in recent years, been extensively investigated and applied as polymer composite reinforcement. These investigations and applications initiatives were discussed in review articles and book chapters ${ }^{9-17}$. In particular, it was reported for sisal, ramie, curaua, jute, bamboo, coir, piassava and buriti fibers that the tensile strength varies with the inverse of the diameter ${ }^{13}$. A simple mathematical hyperbolic correlation was found to provide a reasonable adjustment between the ultimate tensile stress $\bar{\sigma}$ and the fiber equivalent diameter $\mathbf{d}$ : 
$\bar{\sigma}=\mathrm{A} / \mathrm{d}+\mathrm{B}$

where $\mathbf{A}$ and $\mathbf{B}$ are characteristic constants for each type of fiber. The reason for a general relationship specified by Equation 1 was given in terms of defects and flaws, typical of a lignocellulosic structure ${ }^{13}$. This inverse correlation, so far, has not been investigated for the fiber extracted from the pineapple plant (Ananas comosus) and generally known as PALF.

Despite a number of works on the properties of PALF and reinforced polymer composites ${ }^{25-32}$, limited information exist regarding its engineering applications. In fact, the pineapple is better known as a tropical fruit, illustrated in Figure 2, associated with drinks and a fibrous edible pulp.

Table 1 presents some relevant mechanical properties and structural composition reported for PALF in recent overview papers on lignocellulosic fibers ${ }^{15,30}$. In this table, there is apparently a mistake concerning the elastic modulus of $1.44 \mathrm{GPa}$ presented by Faruk et al. ${ }^{15}$. The values of 25-82 GPa of Satyanarayana et al. ${ }^{30}$ appear to be the correct ones. It is important to notice in Table 1 that the PALF tensile strength was found to vary within a great dispersion
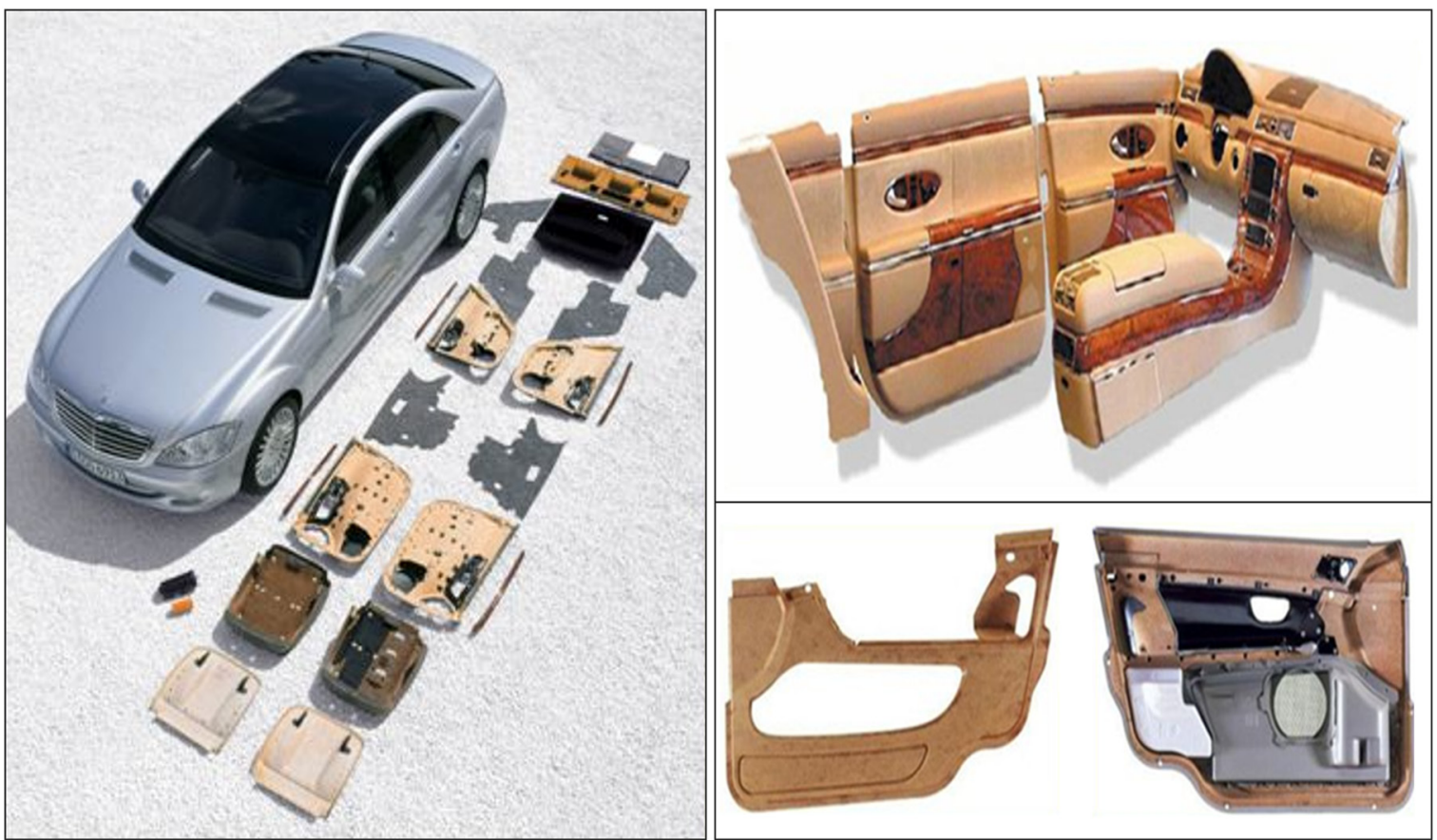

Figure 1. Automobile components based on polymer composites reinforced with lignocellulosic fibers.

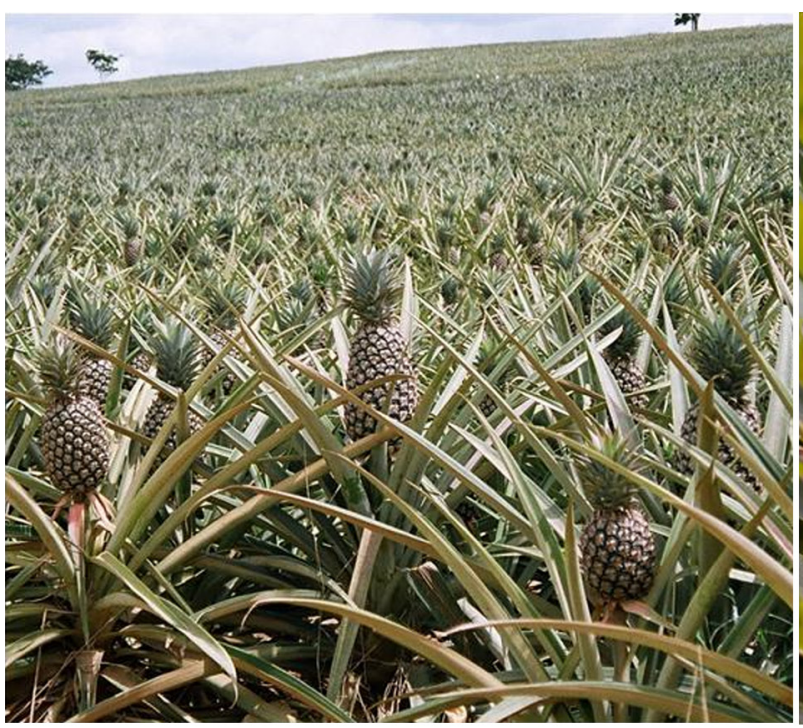

(a)

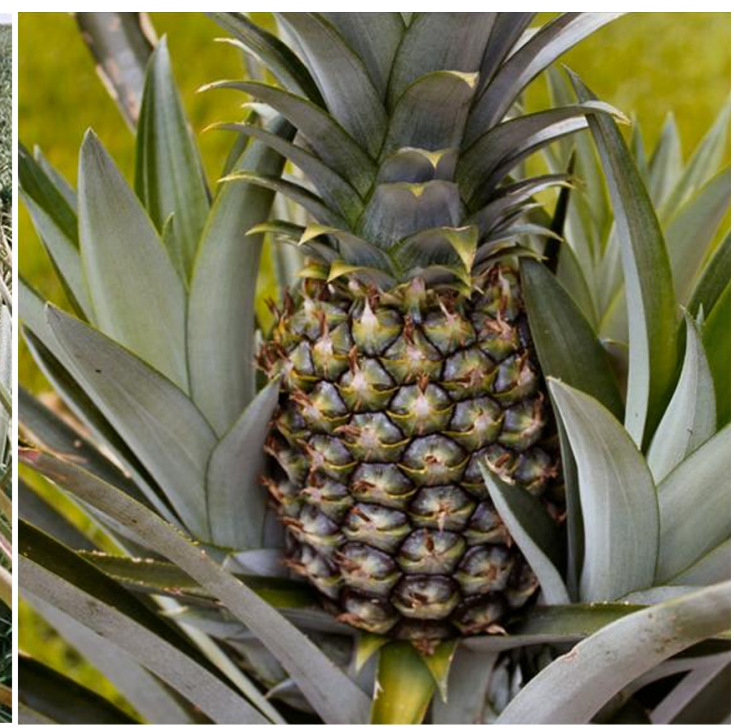

(b)

Figure 2. Pineapple plantation (a) and fruit with leaves (b). 
Table 1. Mechanical properties and structural compositions of pineapple leaf fibers.

\begin{tabular}{ccccccc}
\hline $\begin{array}{c}\text { Tensile Strength } \\
(\mathbf{M P a})\end{array}$ & $\begin{array}{c}\text { Elastic Modulus } \\
\mathbf{( G P a )}\end{array}$ & $\begin{array}{c}\text { Total Strain at } \\
\text { Rupture } \mathbf{( \% )}\end{array}$ & $\begin{array}{c}\text { Density } \\
\left(\mathbf{g} / \mathbf{c m}^{\mathbf{3}}\right)\end{array}$ & $\begin{array}{c}\text { Cellulose } \\
(\mathbf{w t} \%)\end{array}$ & $\begin{array}{c}\text { Lignin } \\
(\mathbf{w t} \%)\end{array}$ & Reference \\
\hline $400-627$ & 1.44 & 14.5 & $0.8-1.6$ & 81 & 12.7 & 15 \\
$180-748$ & $25-82$ & $2-3.2$ & 1.4 & 83 & 12 & 30 \\
\hline
\end{tabular}

of values. This represents a problem for the design of a composite reinforced with PALF.

The possible use of PALF as an engineering material depends on the precise identification of its mechanical properties, especially the tensile strength. Since no investigation has been conducted so far on the diameter influence, the objective of the present work was to determine with statistical precision the PALF correlation between its ultimate tensile strength and equivalent diameter by means of Weibull analysis.

\section{Experimental Procedure}

The basic material used in this work was untreated PALF, illustrated in Figure 3. These fibers were donated by the Brazilian firm Permatec Triangel. The lot of as-received PALF was cleaned and dried in a stove at $60^{\circ} \mathrm{C}$ for 24 hours. A diameter analysis was performed on one hundred fibers randomly removed from the as-received lot. Each fiber was measured in five different points along the length and then $90^{\circ}$ rotated to be measured again, assuming a cylindrical shape. The rotation guarantees an equivalent value of the mean diameter for each fiber. Figure 4 shows the histogram for the distribution of PALF diameters by conventionally considering 6 diameter intervals.

In addition to the one hundred fibers initially considered in the histogram, for each interval in Figure 4 of equivalent diameter, 20 other fibers were selected. All these fibers were then individually tensile tested at $25 \pm 2{ }^{\circ} \mathrm{C}$ in a model 5582 Instron machine. Specials grips were used to avoid both fiber slippage and damage. The test length was $10 \mathrm{~cm}$ and the strain rate $2.1 \times 10^{-4} \mathrm{~s}^{-1}$. Values obtained for the tensile strength, i.e. the ultimate stress, were statistically interpreted by means of the Weibull Analysis computer program.

The Weibull statistical analysis is based on a cumulative distribution function:

$\mathrm{F}(\mathrm{x})=1-\exp \left[-(\mathrm{x} / \theta)^{\beta}\right]$

where $\theta$ and $\beta$ are mathematically known as the shape and scale parameters. Equation 2 can be conveniently modified into a linear expression by double application of logarithm:

$\ln \ln \left(\frac{1}{1-\mathrm{F}(\mathrm{x})}\right)=\beta \ln \mathrm{x}-(\beta \ln \theta)$

In the present case of PALF strength dependence with diameter, $\beta$ is the slope of Equation 3 and indicated as Weibull modulus, while $\theta$ is the characteristic strength. Using the 20 experimental strength data for each interval in Figure 4 associated with an average equivalent diameter, the computer program constructed the linear graph of Equation 3 and calculated the Weibull parameters.

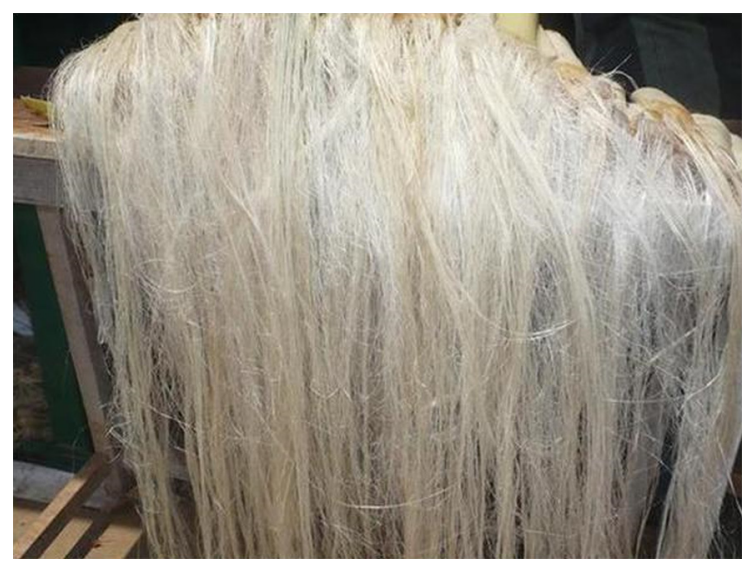

Figure 3. Pineapple fibers, PALF, extracted from the leaves of Ananas comosus.

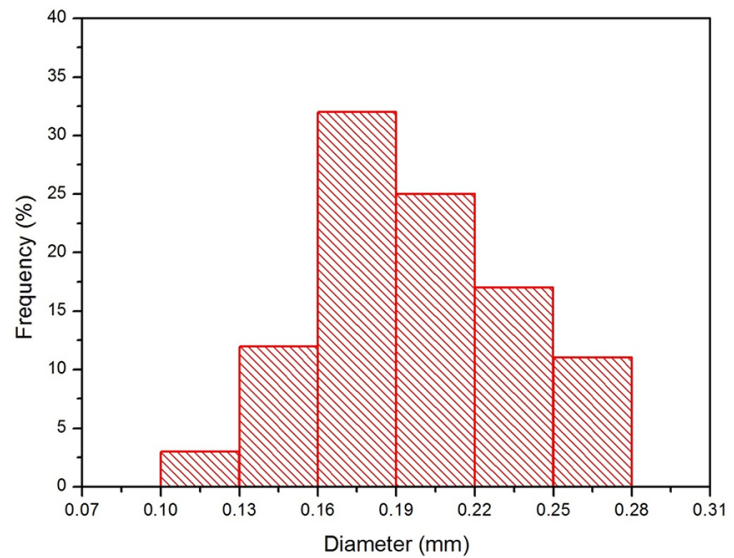

Figure 4. Histogram of the statistical frequency of fibers within six conventional diameter intervals.

\section{Results and Discussion}

Based on the maximum load (L) obtained from curves such as those illustrated in Figure 5, the tensile strength $\left(\sigma_{\mathrm{m}}\right)$ was determined for each fiber by the following equation:

$\sigma_{\mathrm{m}}=4 \mathrm{~L} / \pi \mathrm{d}^{2}$

where $d$ is the equivalent diameter in Figure 4.

The values of $\sigma_{\mathrm{m}}$ were then statistically analyzed by means of the Weibull method applied for the 20 fibers associated with each of the six diameter intervals shown in the histogram of Figure 4. As aforementioned, the Weibull Analysis program provided the probability diagram plots of reliability vs. location parameter associated with Equation 3 for all diameter intervals. These Weibull linear plots are shown in Figure 6. Here it should be noted that all plots in Figure 6 

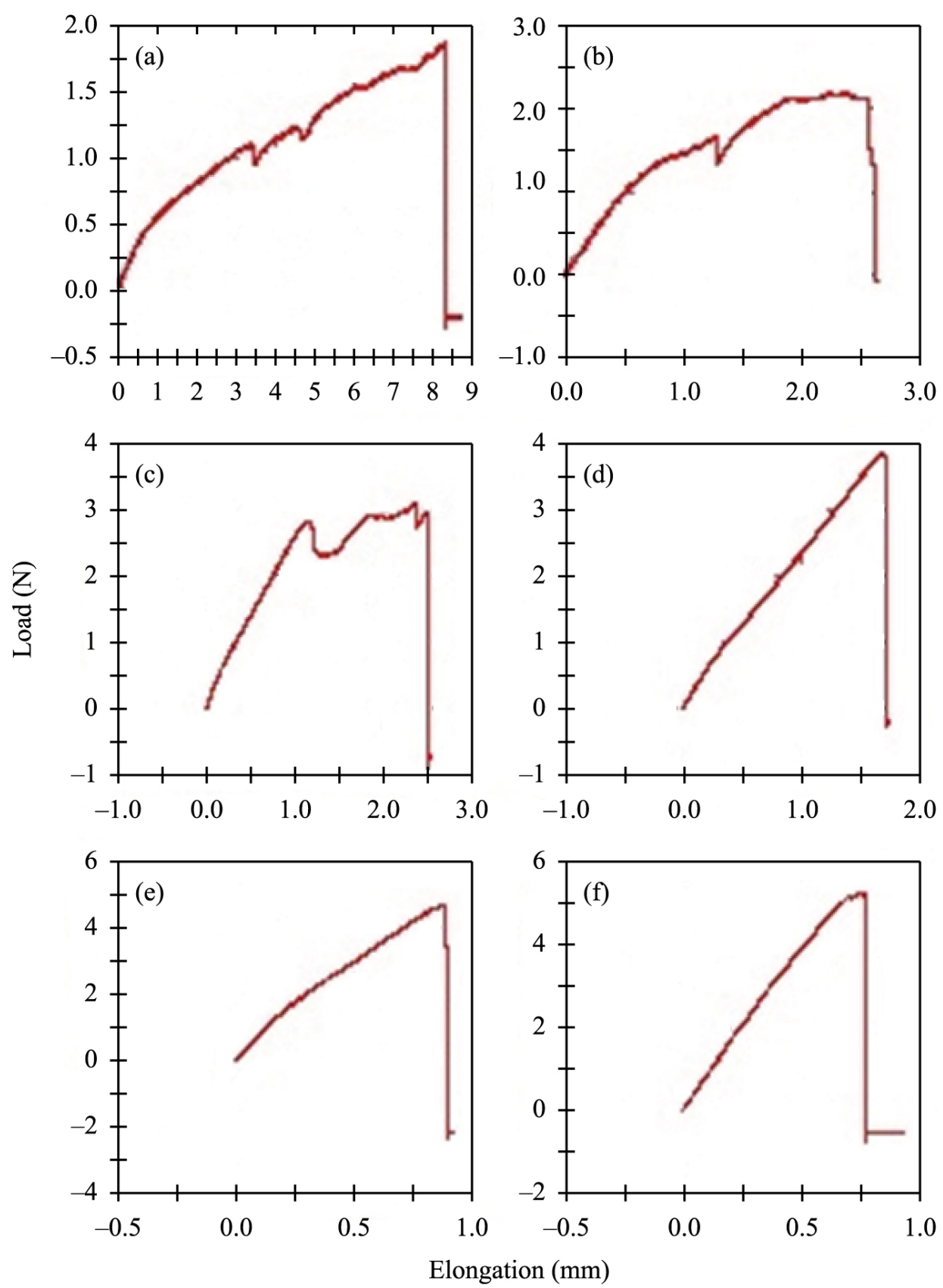

Figure 5. Typical PALF tensile load versus elongation for the different equivalent diameter intervals: (a) $0.10-0.13$; (b) $0.13-0.16$; (c) $0.16-0.19$; (d) $0.19-0.22$; (e) $0.22-0.25$; (f) $0.25-0.28 \mathrm{~mm}$.

are unimodal, i.e., with just one single straight line fitting the points at each interval. This indicates similar mechanical behavior of all fibers within the same diameter interval.

The Weibull Analysis program also provided the corresponding characteristic strength $(\theta)$, the Weibull modulus $(\beta)$ and the precision adjustment $\left(\mathrm{R}^{2}\right)$ parameters. The values of these parameters as well as the average mechanical strength and associated statistical deviations, based on the Weibull distribution, are presented in Table 2. Here it is important to mention that the average strength and deviation are determined within the Weibull statistic and not as a simple sum of values divided by the number of the samples with corresponding standard deviation.

The variation of the characteristic strength with the average fiber equivalent diameter for each one of its intervals is shown in Figure 7. In this figure, there is a clear tendency for the $\theta$ parameter to vary inversely with the average PALF fiber diameter. This means that the thinner the fiber the higher tends to be the characteristic strength. Furthermore, the corresponding values of $\beta$ and $\mathrm{R}^{2}$, shown in Table 2, statistically support the inverse correlation between $\theta$ and the average diameter $\mathbf{d}(\mathrm{mm})$. By means of a mathematic 
Table 2. Weibull parameters for the tensile strength of PALF fibers associated with different diameter interval.

\begin{tabular}{cccccc}
\hline $\begin{array}{c}\text { Diameter Interval } \\
(\mathbf{m m})\end{array}$ & $\begin{array}{c}\text { Weibull Modulus, } \\
\boldsymbol{\beta}\end{array}$ & $\begin{array}{c}\text { Characteristic } \\
\text { Strength, } \boldsymbol{\theta} \\
(\mathbf{M P a})\end{array}$ & $\begin{array}{c}\text { Precision } \\
\text { Adjustment, } \mathbf{R}^{\mathbf{2}}\end{array}$ & $\begin{array}{c}\text { Average Tensile } \\
\text { Strength } \\
(\mathbf{M P a})\end{array}$ & $\begin{array}{c}\text { Statistical } \\
\text { Deviation } \\
(\mathbf{M P a})\end{array}$ \\
\hline $0.10<\mathrm{d}<0.13$ & 2.171 & 326.8 & 0.9249 & 289.4 & 140.5 \\
$0.13<\mathrm{d}<0.16$ & 5.260 & 140.1 & 0.9693 & 129.0 & 28.2 \\
$0.16<\mathrm{d}<0.19$ & 4.928 & 89.0 & 0.9369 & 81.7 & 18.9 \\
$0.19<\mathrm{d}<0.22$ & 2.780 & 77.3 & 0.9875 & 68.8 & 26.8 \\
$0.22<\mathrm{d}<0.25$ & 2.003 & 77.2 & 0.9514 & 68.4 & 35.7 \\
$0.25<\mathrm{d}<0.28$ & 2.841 & 49.8 & 0.9726 & 44.4 & 16.9 \\
\hline
\end{tabular}

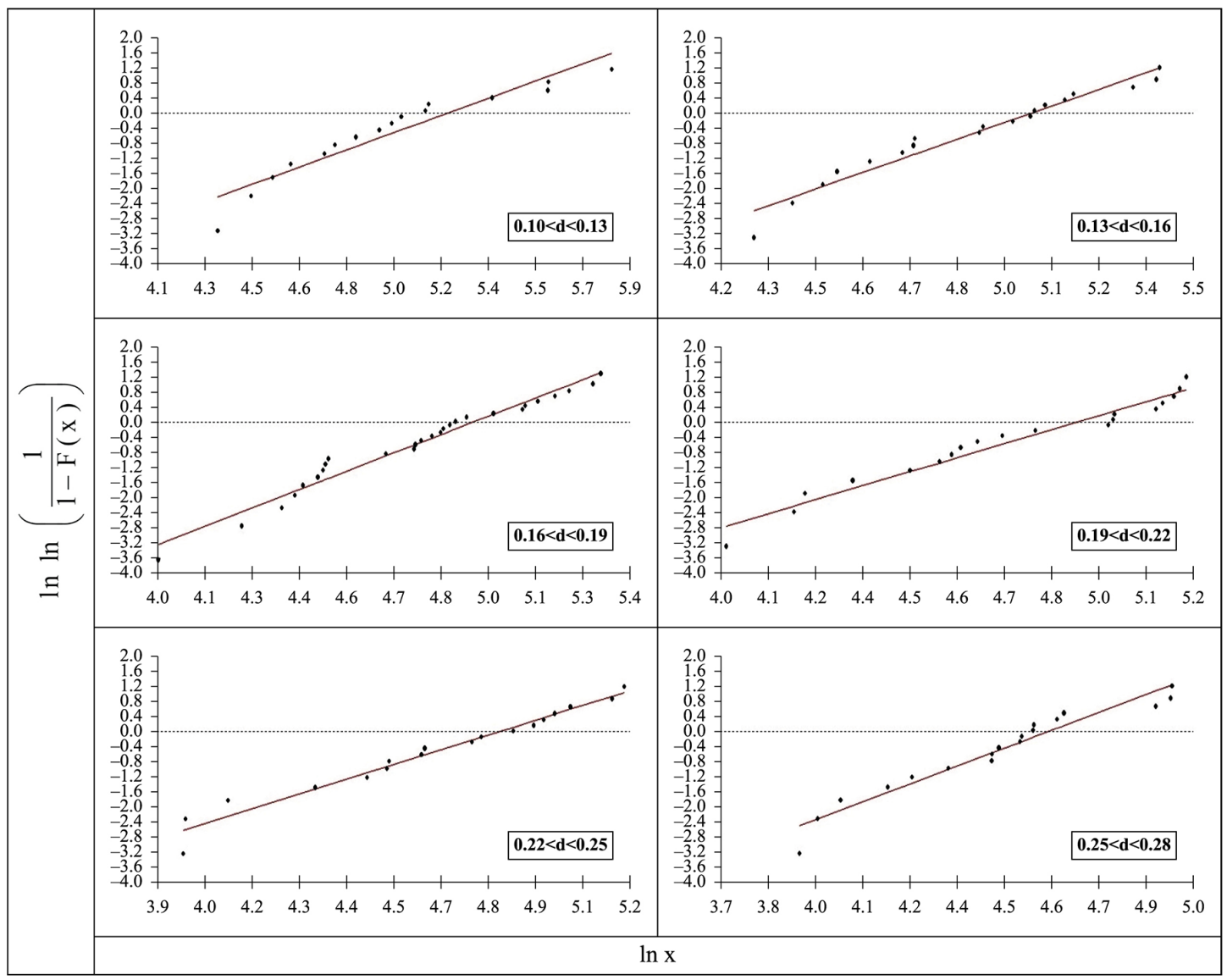

Figure 6. Weibull diagrams for PALF tensile strength in different intervals of diameter.

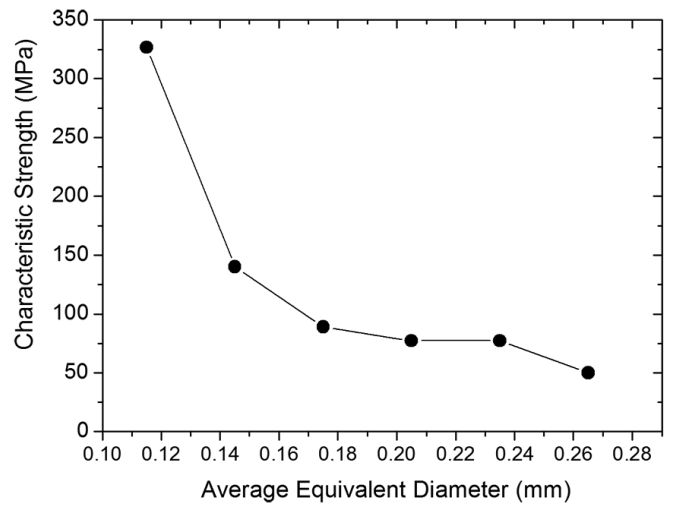

Figure 7. Variation of the PALF Weibull characteristic strength with the corresponding fiber equivalent diameter for each interval in Figure 4. correlation, a hyperbolic type of equation was adjusted to fit the data in Figure 7.

$\theta(\mathrm{MPa})=51.9 / \mathrm{d}-169$

In order to analyze the physical meaning of Eq. (5), the Weibull average tensile strength, $\bar{\sigma}_{\mathrm{m}}$, presented for the PALF in Table 2 was plotted as a function of the equivalent diameter in Figure 8. In this figure, an apparent hyperbolic inverse correlation also exists between $\bar{\sigma}_{\mathrm{m}}$ and $\mathbf{d}$ within the error bars (Weibull statistical deviations) and investigated limits.

$\bar{\sigma}_{\mathrm{m}}=25.7 / \mathrm{d}-55$

One should note that the large dispersion (error bars) in the values of the tensile strength in Figure 8, particularly for the thinner fibers, is due to the heterogeneous and random structural aspects of the biological process of formation of 
any lignocellulosic fiber ${ }^{7-17}$, such as the PALF fibers in this work. As a consequence, one might also consider a straight line passing within the error bars as a possible correlation

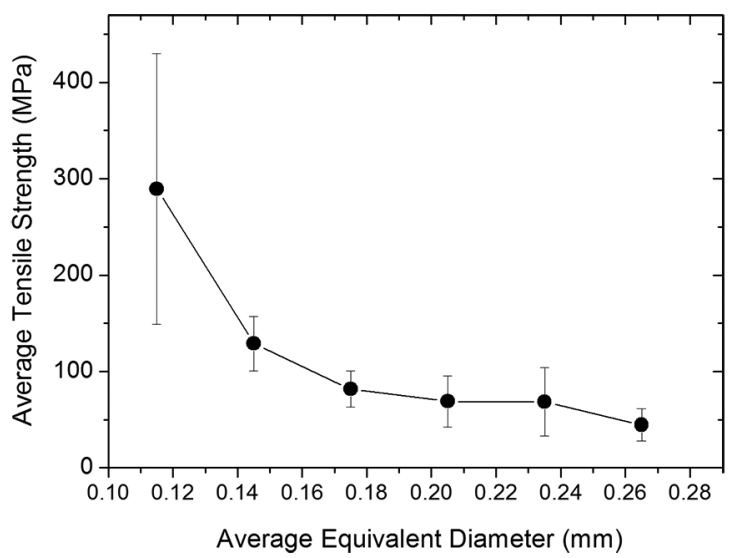

Figure 8. Variation of the PALF Weibull average strength with the corresponding fiber equivalent diameter for each interval in Figure 4. between $\bar{\sigma}_{\mathrm{m}}$ and $\mathbf{d}$. In this case, the tensile strength could be interpreted as varying linearly with the diameter. However, the variation of $\theta$ with $\mathbf{d}$ in Figure 7 , suggests that an inverse correlation fits better the experimental results for the PALF fibers. Based on Equations 5 and 6 it is suggested that, as in others lignocellulosic fibers ${ }^{15,16}$, a hyperbolic type of mathematical equation is the best statistical correlation between the tensile strength and the diameter of PALF.

The microfibrillar nature of the PALF could also be responsible for the results in Figure 8. As illustrated in Figure 9a, the thinner fiber, with $\mathrm{d}=0.11 \mathrm{~mm}$ display a more uniform structure with simultaneous rupture of its microfibrils, shown in Figure 9b. By contrast, the thicker fiber with $\mathrm{d}=0.25 \mathrm{~mm}$ in Figure $9 \mathrm{c}$ has more defects and microstructural porosity associated with heterogeneous rupture of microfibrils, Figure 9d. In other words, the thinner fibers tend to be more uniform with more close packed microfibrils. This contributes to fiber resisting cross section areas with less empty spaces and, consequently, should display higher strength.

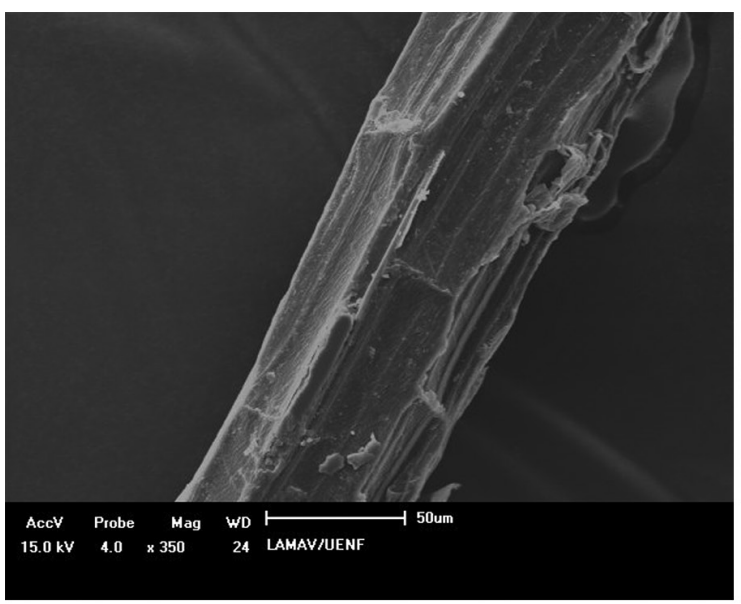

(a)

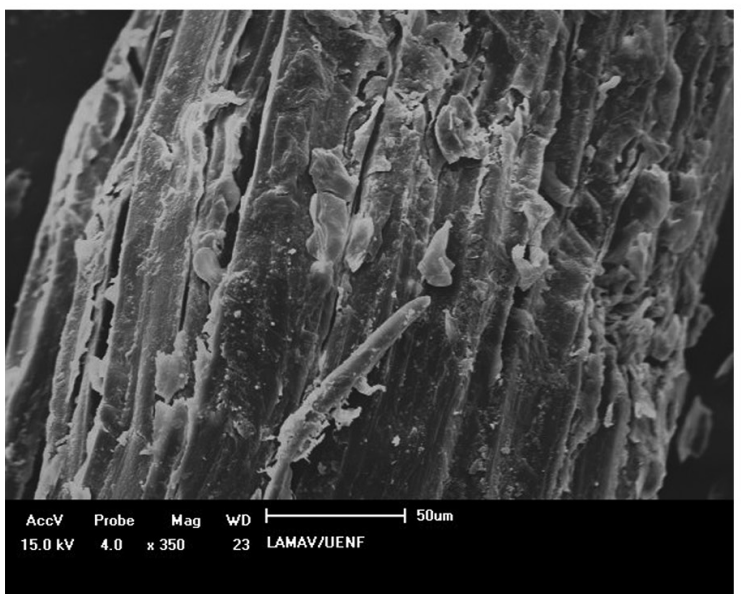

(c)

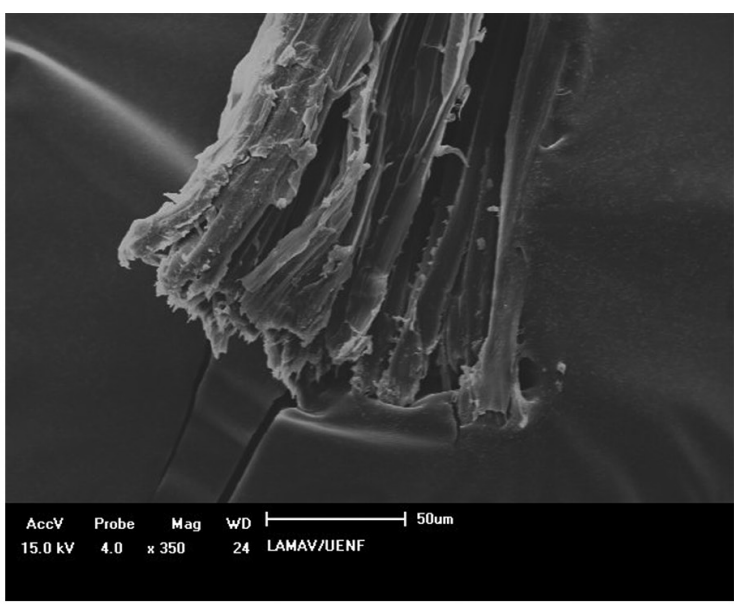

(b)

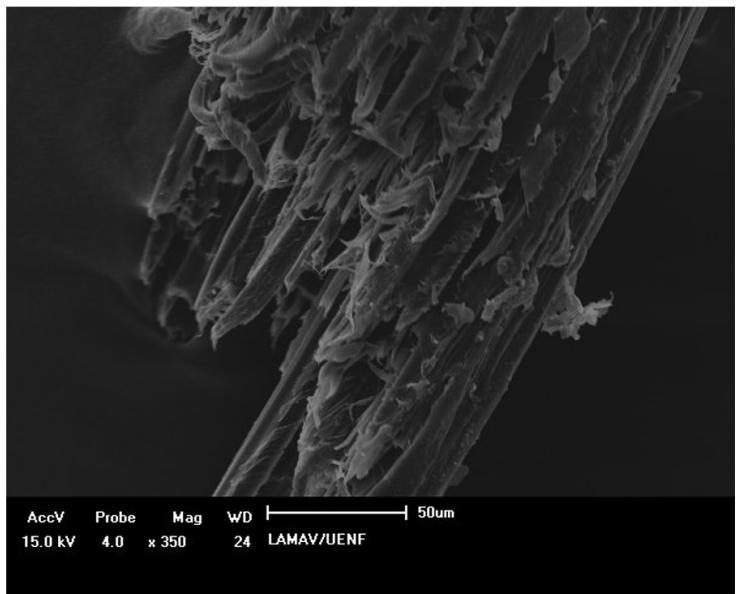

(d)

Figure 9. SEM micrographs of PALF. Thinner fiber, $d=0.11 \mathrm{~mm}$ : (a) general aspect and (b) fracture tip. Thicker fiber, $d=0.25 \mathrm{~mm}$ : (c) general aspect and (d) fracture tip. 
As a final remark, it should be mentioned that an inverse correlation such as that in Equations 5 and 6 could allow, in practice, a selection of stronger thinner PALF to effectively reinforced polymer composites with improved mechanical properties.

\section{Conclusions}

- A Weibull statistical analysis of tensile-tested pineapple leaf fibers (PALF) revealed an inverse correlation between the tensile strength and the fiber diameter. This correlation indicates a possible hyperbolic mathematical equation to associate the PALF strength with its diameter.

\section{References}

1. Callister WD Jr and Rethwisch DG. Materials science and engineering: an introduction. 8th ed. New York: John Wiley \& Sons; 2010.

2. Agarwal BD, Broutman LJ and Chandraskekhara K. Analysis and performance of fiber composites. 3rd ed. Hoboken: Wiley; 2006.

3. Mallick PK. Fiber-reinforced composite: materials, manufacturing and design. 3rd ed. Boca Raton: CRC Press; 2008.

4. Chawla KK. Composite materials science and engineering. 3rd ed. New York: Springer; 2009.

5. Gore A. An inconvenient truth: the planetary emergency of global warming and what we can do about it. Emmaus: Rodale Press; 2006.

6. Mohanty AK, Misra M and Hinrichsen G. Biofibers, biodegradable polymers and biocomposites: an overview. Macromolecular Materials and Engineering. 2000; 276(1):1-24. http://dx.doi. org/10.1002/(SICI)1439-2054(20000301)276:1<1::AIDMAME1>3.0.CO;2-W.

7. Mohanty AK, Misra M and Drzal LT. Sustainable bio-composites from renewable resources: opportunities and challenges in the green materials world. Journal of Polymers and the Environment. 2002; 10(1/2):19-26. http://dx.doi.org/10.1023/A:1021013921916.

8. Netravali AN and Chabba S. Composites get greener. Materials Today. 2003; 6(4):22-29. http://dx.doi.org/10.1016/S13697021(03)00427-9.

9. Crocker J. Natural materials innovative natural composites. Materials Technology. 2008; 2-3(3):174-178. http://dx.doi. org/10.1179/175355508X373378.

10. John MJ and Thomas S. Biofibers and biocomposites. Carbohydrate Polymers. 2008; 71(3):343-364. http://dx.doi. org/10.1016/j.carbpol.2007.05.040.

11. Satyanarayana KG, Arizaga GGC and Wypych F. Biodegradable composites based on lignocellulosic fibers: an overview. Progress in Polymer Science. 2009; 34(9):982-1021. http:// dx.doi.org/10.1016/j.progpolymsci.2008.12.002.

12. Monteiro SN, Lopes FPD, Ferreira AS and Nascimento DCO. Natural fiber polymer matrix composites: cheaper, tougher and environmentally friendly. JOM. 2009; 61(1):17-22. http:// dx.doi.org/10.1007/s11837-009-0004-z.

13. Monteiro SN, Lopes FPD, Barbosa AP, Bevitori AB, Silva ILA and Costa LL. Natural lignocellulosic fibers as engineering materials: an overview. Metallurgical and Materials Transactions A: Physical Metallurgy and Materials Science. 2011; 42(10):29632974. http://dx.doi.org/10.1007/s11661-011-0789-6.
- SEM observations provided evidences that a thicker PALF, with more microfibrils as well as defects and porosity than a thinner one, could undergo rupture at a comparatively lower stress.

- Statistically, the larger distribution of micro fibrils mechanical resistances of the thicker fiber also provides a higher chance that a weaker fibril to rupture shortly than any of the fewer fibrils of the thinner fiber.

\section{Acknowledgements}

The authors thank the support to this investigation by the Brazilian agencies: CNPq, CAPES and FAPERJ.

14. Kalia S, Kaith BS and Kaurs I, editors. Bio-and nano-polymer composites. Berlin: Springer-Verlag; 2011.

15. Faruk O, Bledzki AK, Fink HP and Sain M. Biocomposites reinforced with natural fibers. Progress in Polymer Science. 2012; 37(11):1555-1596. http://dx.doi.org/10.1016/j. progpolymsci.2012.04.003.

16. Thakur VK, Thakur MK and Gupta RK. Review: raw natural fibers based polymer composites. International Journal of Polymer Analysis and Characterization. 2014; 19(3):256-271. http://dx.doi.org/10.1080/1023666X.2014.880016.

17. Carpenter JS, Bai C, Hwang JY, Ikhmayier S, Li B, Monteiro SN, Peng Z and Zhang M. Characterization of minerals, metals and materials. Hoboken: John Wiley \& Sons; 2014.

18. Corbière-Nicollier T, Laban BG, Lundquist L, Leterrier Y, Manson JAE and Jolliet O. Life cycle assessment of biofibres replacing glass fibres as reinforcement in plastics. Resources, Conservation and Recycling. 2001; 33(4):267-287. http://dx.doi. org/10.1016/S0921-3449(01)00089-1.

19. Wambua P, Ivens I and Verpoest I. Natural fibers: can they replace glass and fibre reinforced plastics? Composites Science and Technology. 2003; 63(1):1259-1264. http://dx.doi.org/10.1016/ S0266-3538(03)00096-4.

20. Joshi SV, Drzal LT, Mohanty AK and Arora S. Are natural fiber composites environmentally superior to glass fiber reinforced composites? Compos Part A. 2004; 35(3):371-376. http://dx.doi. org/10.1016/j.compositesa.2003.09.016.

21. Marsh G. Next step for automotive materials. Materials Today. 2003; 6(4):36-43. http://dx.doi.org/10.1016/S13697021(03)00429-2.

22. Holbery J and Houston D. Natural fiber reinforced polymer composites in automotive applications. JOM. 2006; 58(11):8086. http://dx.doi.org/10.1007/s11837-006-0234-2.

23. Zah R, Hischier R, Leão AL and Braun I. Curaua fibers in automobile industry: a sustainability assessment. Journal of Cleaner Production. 2007; 15(1):1032-1040. http://dx.doi. org/10.1016/j.jclepro.2006.05.036.

24. Herrera-Franco PJ and Valadez-González A. Mechanical properties of continuous natural fibre-reinforced polymer composites. Compos Part A. 2004; 35(3):339-345. http://dx.doi. org/10.1016/j.compositesa.2003.09.012.

25. George J, Bhagawan SS and Thomas S. Thermogravimetric and dynamic mechanical thermal analysis of pineapple fibre reinforced polyethylene composites. Journal of Thermal Analysis. 1996; 47(4):1128-1140. http://dx.doi.org/10.1007/ BF01979452. 
26. George J, Bhagawan SS and Thomas S. Effects of environment on the properties of low density polyethylene composites reinforced with pineapple leaf fibre. Composites Science and Technology. 1998; 58(9):1471-1485. http://dx.doi.org/10.1016/ S0266-3538(97)00161-9.

27. Luo S and Netravali AN. Mechanical and thermal properties of environment-friendly green composites made from pineapple leaf fibers and poly (hydroxybutytate-co-valerate) resin. Polymer Composites. 1999; 20(3):367-378. http://dx.doi.org/10.1002/ pc. 10363.

28. Mangal R, Saxena NS, Sreekala MS, Thomas S and Singh K. Thermal properties of pineapple leaf fiber reinforced composites. Materials Science and Engineering A. 2003; 339(1-2):281-285. http://dx.doi.org/10.1016/S0921-5093(02)00166-1.

29. Arib RMS, Sapuan SM, Ahmad MMHM, Paridah MT and Zaman MHDK. Mechanical properties of pineapple leaf fiber reinforced polypropylene composites. Materials \& Design. 2006; 27(5):391-396. http://dx.doi.org/10.1016/j.matdes.2004.11.009.

30. Satyanarayana KG, Guimarães JL and Wypych F. Studies on lignocellulosic fibers of Brazil. Part I: source, production, morphology, properties and applications. Compos Part A. 2007; 38(1):1694-1709. http://dx.doi.org/10.1016/j. compositesa.2007.02.006.

31. Threepopnatkul P, Kaerkitcha N and Athipongarporn N. Effect of surface treatment on performance of pineapple leaf fiberpolycarbonate composites. Compos Part B. 2009; 40(7):628-632. http://dx.doi.org/10.1016/j.compositesb.2009.04.008.

32. Abraham E, Deepa B, Pothan LA, Jacob M, Thomas S, Cvelbar $\mathrm{U}$, et al. Extraction of nanocellulose fibrils from lignocellulossic fibers: a novel approach. Carbohydrate Polymers. 2011; 86(4):1468-1475. http://dx.doi.org/10.1016/j.carbpol.2011.06.034. 